\title{
ON THE OCCURRENCE
}

OP

\section{TUBERCULAR DISEASE OF THE TESTIS}

\author{
AS A LOCAL AFFECTION,
}

\section{PARTICULARLY WITH REFERENCE TO THE DESIRABILITY OF EARLY OASTRATION IN CERTAIN CASES.}

BY

\author{
WILLIAM H. BENNETT, F.R.C.S.,
} SURGRON TO ST. GRORGE'S HOSPITAL.

Received July 4th, 1887-Read January 24 th, 1888.

THE basis of the following paper is a report of five cases which came under observation in my out-patient practice, and which are recorded as they seem to present, for reasons afterwards discussed, some points of interest connected with the possible origin of tubercular testis as a purely local affection, its tendency to generalisation as shown by the implication of distant parts, especially the spine, the relation of the disintegration of the original disease to general tubercular infection, and the desirability of early castration in certain cases.

CASE 1. - In January, 1882, a boy, æt. 9, was brought to the hospital on account of a "swollen testicle." Four months previously he had received a 
blow on the scrotum. Considerable swelling and great pain followed, but subsided almost entirely in a fortnight.

No further notice was taken of the matter till one month later, when the testicle became painful, swollen, and tender. The general health was not in any way affected and the boy attended school, running about much as usual, till three or four weeks before he came under my care, when rapid increase of the swelling occurred, and was followed, in a few days, by the bursting of an abscess over the affected organ. After this he became pale, thin and languid.

The family history was absolutely free from any evidence of tubercular disposition, the boy had always been well fed, healthily housed, and had, up to the date of the injury to the testicle, never suffered from a day's illness.

When first seen by me the patient was rather thin and pale. The right epididymis was much swollen, above it was nodulated, below the scrotum was boggy, and presented a sinus discharging thick pus. The testicle itself was somewhat hard. There was not much tenderness and very little pain. A most careful general examination failed to detect any sign of disease in other parts, including the opposite epididymis and testis, both seminal vesicles and ducts.

Three weeks later the condition of the testis was much the same; the boy was better in general health, but it was noticed that he held himself stiffly in walking. The spine was then found to be rigid and tender in the dorsolumbar region. No pain in the back had been complained of and the mother was unaware of anything being wrong in that region. The seminal vesicles and left epididymis and testicle still showed no evidence of disease.

Although the mother was strongly urged to allow the boy to come into the hospital she declined to do so as she could not realise that the spinal disease was of consequence, and ceased to attend.

Casi 2. - A labourer, æt. 30, applied for treat- 
ment in December, 1883. A year before he had contracted gonorrhœa, which was followed by "swelled testicle." When recovering from this he struck the testicle against the back of a chair, after which the pain and swelling recurred, then diminished, but never altogether disappeared.

Five months before coming under observation a small abscess burst at the lower part of the scrotum and remained continually open. His general health had in no way suffered. He thought nothing of the abscess, and only came to the hospital on account of a "touch of lumbago" which came on suddenly whilst he was lifting a heavy weight ten days before.

He had never suffered from syphilis, and the family history was perfect. In appearance the man was strong and healthy. The right testis was universally swollen, hard in some parts, boggy in others. At the lower part of the scrotum were two sinuses from which came curdy pus.

The spine at the junction of the dorsal and lumbar regions was perfectly rigid and tender on pressure. No disease could be detected in either seminal vesicle, duct, opposite epididymis, testicle, prostate gland, or other organ.

The patient could not be made to understand the serious character of his disease, declined to come into the hospital, and was not seen again.

Case 3.-A cabman, æt. 30, applied at the hospital in January, 1884. Five months before, a blow on the left testicle was followed by much pain and swelling, which did not entirely subside. He had never suffered from gonorrhœa or syphilis, his family history was perfect, and he had always been a remarkably strong and healthy man.

On examination, the patient appeared to be in robust general health. The left epididymis was hard and nodular, there was some tenderness at the lower part, but no softening was apparent. The testicle itself seemed quite natural. A thorough investigation fuiled to find 
disease in any other part, including the opposite testicle and epididymis, prostate gland, seminal vesicles, and ducts. After his first visit the patient was not seen again for six weeks, when he returned with more swelling about the testicle. At the lower part of the scrotum was a discharging sinus which had formed about ten days previously. The seminal vesicles, prostate, opposite epididymis, and testes remained healthy, but the dorsolumbar spine was absolutely rigid, although he was entirely unaware of the existence of anything wrong with his back. Over the last dorsal spinous process, which seemed rather prominent, deep pressure elicited slight pain. As in the last case I could not induce the man to believe that the spine was seriously affected. He continued to attend for about two months, during which the disease steadily progressed, but the opposite testis, \&c., did not become involved. $\mathrm{He}$ declined to consider the question of castration, and I ultimately lost sight of him.

CASE 4.-A messenger, æt. 16, first came under my care as an out-patient in May, 1884, on account of a swelling in the right side of the scrotum which had been caused by an injury received in the previous January. He had always enjoyed excellent health, had never suffered from gonorrhœa or syphilis, and his family history was perfect.

The lad was healthy looking and well nourished. The right epididymis was enlarged, nodular, slightly tender, but in no part soft. The testicle itself seemed normal, and no disease could be detected in the opposite testis, epididymis, seminal vesicles, or other organ. The testicle gradually became involved. At the end of June an abscess formed at the lower part of the epididymis and was laid open.

I then recommended castration, but the patient would not consent to the operation. A month subsequently some rigidity was detected in the spine over the lower dorsal region, deep pressure caused pain, but there was 
no discomfort during ordinary movements. The seminal vesicles and opposite testis remained healthy. Castration was again proposed but negatived by the patient. A plaster spinal jacket was adapted and the boy went about his work as usual. A fortnight after this rapid swelling came on in the left epididymis, the testicle soon became affected, an abscess formed and was opened. The plaster jacket was not removed until September when the patient was taken into the hospital. The spinal disease had then increased considerably, the area of rigidity was greater, and there was commencing angular curvature. Some hard nodules could now be felt in the seminal vesicles and the vasa deferentia were much thickened. Both testicles were suppurating freely and discharging curdy pus through various sinuses.

A poroplastic support was now fitted, and he resumed his occupation, which he followed without discomfort till June, 1885, when he was readmitted on account of a fluctuating swelling in the right iliac region, from which a large quantity of unhealty pus was removed by aspiration.

His general health now broke down, and after a number of complications, the most noteworthy of which was a typical attack of tubercular meningitis, from which he recovered, he ultimately died of general tuberculosis, as shown by post-mortem examination in June, 1886.

Case 5.-A coachman, æt. 41, of strong and healthy appearance, commenced attending at the hospital in December, 1885, on account of some swelling about the right testis, which had followed directly upon an injury received about a year before. The swelling, which was extremely painful and tender at first, gradually diminished, but never entirely disappeared, subsequently it increased, and the pain and tenderness, which had quite left him, again came on.

He had always been remarkably well and strong, there was no suspicion of tubercular tendency in his family history, but he had suffered from a chancre twenty-three 
years ago, which was followed by no other symptoms so far as he could recollect.

On examination, the right epididymis was large, hard, and nodular, the testicle itself was a little swollen and tender, but there was no sign of softening. No disease could be detected in any other part, inclusive of the opposite testicle and epididymis, both seminal vesicles and prostate.

At the beginning of January, some softening showed itself about the lower end of the epididymis. An incision was made and some thick pus evacuated. Castration was at this time urged upon the patient, but he declined the operation. Three weeks after this the spine was found to be quite rigid and very slightly tender on deep pressure over the dorso-lumbar region.

Again, the patient declined to allow castration to be performed. Some more breaking down about the epididymis occurred, and on March 23rd, 1886, he was admitted as an in-patient. At this date the spine showed extensive rigidity, there was pain on movement and much tenderness on manipulation. The scrotum was boggy on the affected side and the sinuses were discharging oily pus. There was no evidence of the invasion of any other parts by the disease. The general health had suffered curiously little.

By May 27th there was no indication of improvement in the condition of the spine in spite of absolute rest, the suppuration about the affected testicle and epididymis was more profuse, and the general condition of the patient was becoming unsatisfactory. Castration was now performed, the testicle after removal presenting an admirable example of tubercular disease, both to the naked eye and by the microscope.

Rapid improvement followed the operation, particularly in the condition of the spine, the rigidity decreased at a rate altogether out of proportion to the amount of rest enforced, and at the end of six weeks the patient considered the back perfectly well. The scrotal wound healed 
soundly, but there was for two months some pain about the stump of the cord, which ultimately, however, settled down.

Four months after the operation all pain and tenderness had left the spine and there was merely a suspicion of rigidity. A leather spinal support was fitted and he was allowed to leave the Hospital.

When seen nearly a year after the operation, the spine was supple and entirely natural. $\mathrm{H}_{\Theta}$ was following his occupation as a coachman. Not a sign of disease could be detected in any part of his body.

Remarks. - These cases were selected for record after a most thorough investigation, as they possessed certain important characteristics in common. In each instance the family history was perfect and there was an entire absence of privation, excess, or other condition predisposing in any way to the development of general tubercle. In every case there was, up to the time of the local affection, a perfectly clean bill of health, with the exception of patient No. 5, who had a chancre twenty-three years previously.

The original disease in all the cases was the result of direct irritation, traumatic in four, gonorrhœal in one. In every instance the spine became involved before there was any evidence of tubercle in the seminal vesicle, opposite testis or other part in the immediate neighbourhood of the original disease. The spinal affection was most insidious in its onset and was, at the time of its discovery by me, unsuspected by the patients, excepting No. 2, who found it out for himself accidentally.

In neither of the cases did the spine become implicated until after the breaking down of the original disease, nor did the general health become seriously affected until a considerable period after the formation of abscess.

The occurrence of tubercular disease in parts distant from the testis primarily attacked before the invasion of the corresponding seminal vesicle is, so far as I know, voI. LXXI. 
not recognised as an ordinary or even occasional occurrence and may be taken, I presume, as fairly positive evidence of the commencement of general infection. Why in these particular cases the spinal column should be the part first to show signs of this secondary disease I do not attempt to explain.

The association of disease of the spine with tuberculous testis has been considered by more than one observer, particularly Reclus, who in his monograph on 'Tubercle of the Testicle,' devotes much attention to the matter, but there is, so far as I can ascertain, a remarkable paucity of clinical evidence as to which of the two parts is commonly the seat of the original disease. This is due mainly, I suppose, to the fact that as a rule patients do not come under observation until both parts have become implicated, and in some cases it is possible that the extremely insidious and painless onset of the spinal affection may have allowed it to escape the notice of the surgeon as well as of the patient. Be that as it may, there is in these cases, at all events, no doubt as to the testis being the seat of the original mischief.

The time at which the symptoms of the spinal implication first developed is a matter of much importance, for, as has already been pointed out, no sign of secondary disease of any part showed itself until the occurrence of disintegration and abscess in the part primarily affected, after which at no great interval infection surely followed. From this it is, I think, not unreasonable to infer that the risk of complication in other parts is greatest at the time of the breaking down of the original tubercular material, which therefore constitutes what I venture to call the " dangerous period," and may be taken, I believe, to apply not only to the disease as seen in the testicles but to any local tubercular deposit.

This close connection between the disintegration process referred to and the secondary manifestation of disease may, in the minds of some, no doubt admit of explanation by supposing that the two conditions are merely the outcome 
of pre-existing general tubercle, but in these cases of mine there was no evidence whatever to excite even a suspicion of any tendency to general disease until after the breaking down of the part originally affected, in fact it is difficult to deny that they show as clearly as clinical observation can prove that the disease in the spine was the result of some infective action connected with the primary deposit in the testis.

The recognition of a tubercular disease, primarily of a purely local kind, which tends surely to the implication of other parts at a well-defined stage in the affection, must of necessity have an important bearing upon the treatment of such cases, as it is obvious that the general safety of the patient would be best provided for by the removal of the organ originally diseased upon the appearance of symptoms of disintegration indicating the onset of the "dangerous period."

It is, I believe, not unfrequently asserted that castration in the early stage of tubercular testis is unnecessary if not unjustifiable, since recovery may often occur without operative interference. If by this is meant merely that the abscesses in the testis may dry up and the sinuses heal, I admit the occurrence of such cases, but that recovery in the proper sense, i.e. without the implication of other parts, often occurs in those cases I venture to doubt, for I have examined a considerable number of patients bearing scars and other evidences of " cured" tubercular testis and cannot call to mind a single instance in which latent disease in some other part did not exist. Further, even if it be admitted that spontaneous recovery is possible, it cannot be denied that so long as tubercular material undergoing disintegration is present the patient is in constant danger of general infection; a fact in itself affording sufficient justification for the sacrifice of a diseased testicle, the loss of which, seeing that the organ is functionally impaired and possibly useless, can hardly be regarded as a serious calamity, excepting for sentimental or domestic 
reasons, especially as the operation for its removal is without risk if done with ordinary care.

The rapid improvement in the condition of the spine in Case 5 after the extirpation of the suppurating testis is a remarkable instance of the advantage of castration after other parts have become affected, and is of interest in connection with the question of operation in the later stages of tuberculous disease.

A careful consideration of the cases recorded above from a clinical point of view appears to me to justify the following conclusions :

1. Inflammation of the testicle or epididymis as the consequence of injury or direct irritation may result in tuberculous disease of a purely local kind, which if left to itself tends surely to generalisation.

2. The greatest tendency to general infection is at a time subsequent to the breaking down of the original deposit, which may therefore be called the "dangerous period."

3. Parts remote from the testis primarily affected may be involved by the disease before it invades either seminal vesicle or opposite epididymis and testicle.

4. The rational treatment for these cases is castration upon the appearance of symptoms of suppuration about the original disease, $i$. $e$. at the onset of the "dangerous period."

(For report of the discussion on this paper, see ' Proceedings of the Royal Medical and Chirurgical Society,' New Series, vol. ii, p. 329.) 